Journal of Systems Science and Information

Jun., 2017, Vol. 5, No. 3, pp. 216-228

DOI: $10.21078 /$ JSSI-2017-216-13

\title{
Investigating the Disparities of China's Insurance Market Based on Minimum Spanning Tree from the Viewpoint of Geography and Enterprise
}

\author{
Chi XIE* \\ College of Business Administration, Hunan University, Changsha 410082, China; Center for Finance \\ and Investment Management, Hunan University, Changsha 410082, China \\ E-mail:xiechi@hnu.edu.cn \\ Yingying ZHOU \\ College of Business Administration, Hunan University, Changsha 410082, China \\ Gangjin WANG \\ College of Business Administration, Hunan University, Changsha 410082, China; Center for Finance \\ and Investment Management, Hunan University, Changsha 410082, China; Center for Polymer \\ Studies and Department of Physics, Boston University, Boston, MA, 02215, USA

\section{Xinguo YAN} \\ College of Business Administration, Hunan University, Changsha 410082, China
}

\begin{abstract}
In this paper, we investigate the disparities of China's insurance market from the viewpoint of geography and enterprise by using the monthly data from January 2006 to December 2015. We divide the whole insurance market into two parts, namely property insurance and personal insurance. By constructing and analyzing minimum spanning trees of insurance market, we obtain the results as follows: (i) The connections between provinces are much closer than those of firms, and there are regional links between neighboring provinces in the minimum spanning tree (MST); and (ii) the domestic funded firms and foreign funded firms form two explicit clusters in the MSTs of property and personal insurance market.
\end{abstract}

Keywords network analysis; minimum spanning tree; China's insurance market; disparity; provincelevel; firm-level

\section{Introduction}

It is a formidable challenge to grasp financial markets' operating rules and forecast their changing trends because they are complex systems with features such as non-linearity, selfsimilarity, heterogeneity and dynamics. The insurance market is one of the essential parts of

Received July 2, 2016, accepted December 19, 2016

Supported by National Natural Science Foundation of China (71373072, 71340014 and 71501066), the China Scholarship Council (201506135022), the Specialized Research Fund for the Doctoral Program of Higher Education (20130161110031) and the Foundation for Innovative Research Groups of the National Natural Science Foundation of China (71521061)

*The corresponding author 
the financial system. Insurance is a useful financial product to avoid loss and provide security for property or lives. Recently, the State Council of China issued a new regulation about the insurance of deposits. It states that it is possible for commercial banks to bankrupt as common enterprises when they are under extreme financial distress, which means that even civilians' deposits also suffer from risk. In the meanwhile, the deposit insurance system is established to protect the benefits of depositors. Despite the upper coverage limit is only Renminbi 0.5 million for a single deposit at present, the deposit insurance system will be playing an increasingly important role in the insurance market for the foreseeable future. Thus, the insurance market will be more prosperous after being stimulated.

A huge body of literature has provided insights on the network analysis in the past two decades by describing dynamic features of specific markets with various methods. One of the most representatives is the minimum spanning tree (MST), which is constructed based on correlation coefficients matrix ${ }^{[1-7]}$. Specifically, the MST is constructed based on the shortest distance between nodes, and excludes redundant distances, which makes it easy to be implemented and contain considerable information with few edges. The MST is explicit to the users with concise figures. The MST network analysis is widely applied to explore features of financial markets, including stock markets ${ }^{[1-9]}$, foreign exchange markets ${ }^{[10-13]}$, currency markets ${ }^{[14]}$, bond markets ${ }^{[15]}$, equity markets ${ }^{[16]}$, real estate markets ${ }^{[17]}$, and also other areas, like layout of radar ${ }^{[18]}$, transportation design ${ }^{[19]}$ and genes expression analysis ${ }^{[20]}$. For instance, Mantegna $^{[1]}$ investigated daily price of stocks index of Dow Jones Industrial Average (DJIA) and Standard and Poor's 500 (S\&P 500) from July 1989 to October 1995, and found that the stocks hierarchical arrangement is a useful economic taxonomy. Lee, et al. ${ }^{[2]}$ examined highfrequency data, namely minute-by-minute data of 50 representative stocks from the Korean stock market starting on 2 January 2009 and ending on 30 December 2009 through MST. They found that in a volatile situation, the network becomes denser and the degree of co-movement of markets becomes stronger than that in a normal situation. Wang, et al. ${ }^{[12]}$ studied a set of 35 major currencies in international foreign exchange (FX) markets from June 2005 to May 2011 and divided the periods into three sub-periods: Before, during and after US sub-prime crises by using the dynamic time wrapping method and MST. Their results indicate that USD (US dollar) is losing its central position in the world while EUR (Euro) is becoming the center in the world currencies passing through the crises, and SGD (Singapore dollar) is turning into a new center of Asian currencies after the crises. Di Matteo, et al. ${ }^{[14]}$ employed two sets of interest rates and got different clusters and corresponding hierarchical structures. Gilmore, et al. ${ }^{[15]}$ used MST to study the patterns of co-movements for a set of 20 government bond market indices and found that the correlations of these markets tend to be close.

Although there is a large amount of works concerning different fields of financial markets with network analysis approaches, nearly no scholars have studied the topology network of insurance markets until now. It is noteworthy that China's insurance markets have enjoyed a surge of prosperity in the last several decades owing to the rapid development of the Chinese economy, but there are some disparities between geographical regions resulting from cultural influence of collectivisms, government intervention and structure of markets ${ }^{[14]}$. With the continuous development of the Chinese economy and improvements of living standards of residents, 
China's insurance market, resumed in 1980, grows rapidly and the average growth rate of the income of insurance premiums is nearly $35 \%$ per year. Meanwhile, the type of insurance also expands from the single property to four major categories, i.e., property, personal, liability and credit insurances. The development process can be divided into three stages. The first stage is the recovery period from 1980 to 1985 . The domestic property and personal insurance business resumed in 1980 and 1982, respectively. During this stage, the People's Insurance Firm of China (PICC) monopolized the insurance market. In addition, the share of the property insurance was much greater than that of the personal insurance. The second stage is the steady phase from 1986 to 1991. The signature event is the foundation of Xinjiang Production and Construction Corps Agriculture and Animal Husbandry Production Insurance Firm (which is named China United later), which broke the monopoly of PICC and promoted the development of China's insurance market. The third stage is the rapid development period from 1992 until now. The milestone is the establishment of Shanghai Branch of American Insurance Assurance (AIA), which is the first foreign funded insurance firm that entered China's insurance market. Thereafter, with the continuous increase of participants in the insurance market, a diversified market structure forms. Furthermore, the market share of personal insurance gradually exceeds that of property insurance. With the increasing of types of insurance and the improvement of insurance service and complement of insurance regulation, China's insurance industry gradually turns into the map consisting of state-owned insurance firms, foreign insurance firms and firms of other categories.

Due to the features of insurance data, we discuss the clustering effects of China's insurance markets from the viewpoint of geography and enterprise by using the MST network analysis methods. Unlike the earlier studies using the stock price or exchange rate as objects, the cumulative income is adopted to accomplish this work, which is similar with the study of Gomez, et al. ${ }^{[21]}$ who used GDP to carry out network analysis. In empirical analysis, we collect monthly cumulative incomes of the property and personal insurances (including life, health and accident insurances) by provinces and firms from January 2006 to December 2015.

The rest of this paper is organized as follows. Section 2 presents the source of data and methodology applied in our study, including the preprocessing of data and the procedure of constructing MST. Empirical results and discussions are demonstrated in Section 3. Section 4 reports the conclusion.

\section{Data and Methodology}

\subsection{Data}

The data used in this paper are monthly cumulative incomes from January 2006 (the earliest data are available) to December 2015, which contain totally 120 sets of data of the property and personal insurance markets. We gain the data from the website of China Insurance Regulation Commission (http://www.circ.gov.cn/web/). We clarify the data into two levels: (i) The province-level data, and (ii) the firm-level data.

The province-level data include the data of Beijing, Tianjin, Hebei, Liaoning, Shanghai, Jiangsu, Zhejiang, Fujian, Shandong, Guangdong, Hainan, Shanxi, Jilin, Heilongjiang, Anhui, Jiangxi, Henan, Hubei, Hunan, Chongqing, Sichuan, Guizhou, Yunnan, Tibet, Shaanxi, Gansu, 
Qinghai, Ningxia, Xinjiang, Inner Mongolia and Guangxi, totally 31 provinces ${ }^{1}$.

For the firm-level data, by excluding firms with incomplete data, we finally choose 24 property insurance firms and 18 personal insurance firms. The property insurance firms contain 18 domestic funded property insurance firms (i.e., Anbang, Anhua, Bohai, Export Credit, Continent, Du-Bang, Sinosafe, Huatai, Ping'an, PICC, CPIC, Taiping, Tian'an, Sunshine, Sunlight, Yong'an, Alltrust and China United) and 6 foreign funded firms (i.e., Tokiomarine, Liberty Mutual, AIU, Chubb, Sompo Japan and Mitsui Sumitomo). As for the foreign funded firms, three of foreign funded property firms (i.e., AIU, Chubb and Liberty Mutual) are from America and the other three firms (i.e., Sompo Japan, Mitsui Sumitomo and Tokiomarine) are from Japan, which may result from the fact that American and Japanese insurance firms enter China's insurance market much earlier than other countries in our empirical study.

The personal insurance firms consist of 9 domestic funded firms (namely China life, China Pacific, Ping An life, New China, Taikang, Taiping, Minsheng, Sino and Union), 8 foreign funded firms, including Manulife-Sinochem (Canada), CITIC prudential (The United Kingdom), Central China (Italy), AIA (America), Aviva-Cofco (The United Kingdom), Cigna \& Cmc (America), Heng An Standard (The United Kingdom), Skandis-basm (The United Kingdom) and an oversea firm Cathay. Comparing with the property insurance market of firm-level, the foreign funded personal insurance firms in China's insurance market are more diverse, which may result from the gradual maturing and opening of China's insurance market.

\subsection{Methodology}

\subsubsection{Data Preprocessing}

Because the original data we obtain are cumulative data, we firstly calculate the income of single month for each year as follows:

$$
I_{i}(t)=C I_{i}(t)-C I_{i}(t-1), \quad t=2,3, \cdots, 12,
$$

where $I_{i}(t)$ is the income of province $i$ at time $t$ (namely month $t$ ) and $C I_{i}(t)$ is the cumulative income of province $i$ from the first month to the $t$-th month. Afterwards, we obtain 120 monthly incomes of each province. In order to get the correlation coefficients between any two provinces, the return $R_{i}(T)$ of province $i$ at $T$ is calculated, which is defined as

$$
R_{i}(T)=\frac{I_{i}(T)-I_{i}(T-1)}{I_{i}(T-1)} \times 100 \%, \quad T=2,3, \cdots, 120 .
$$

The Pearson correlation coefficient between the returns of any two provinces (firms) $i$ and $j$ at given time $t$ is defined as

$$
\rho_{i j}=\frac{\left\langle R_{i} R_{j}\right\rangle-\left\langle R_{i}\right\rangle\left\langle R_{j}\right\rangle}{\sqrt{\left(\left\langle R_{i}^{2}\right\rangle-\left\langle R_{i}\right\rangle^{2}\right)\left(\left\langle R_{j}^{2}\right\rangle-\left\langle R_{j}\right\rangle^{2}\right)}}, \quad i, j=1,2, \cdots, 31,
$$

where $\langle\cdot\rangle$ means the average of corresponding items. The possible values of $\rho_{i j}$ are within the range of -1 to 1 . The values of $-1,0$ and 1 indicate completely negative correlation, no correlation and completely positive correlation between provinces (firms) $i$ and $j$, respectively.

${ }^{1}$ For simplicity, we acknowledge the municipalities and autonomous regions as provinces. 
To examine whether the correlation between the returns exists and is significant, we discuss these monthly returns. Tables $1 \sim 4$ show the correlation coefficients and corresponding significance of different insurance market. Limited to the size of the result table, we only provide the part of the whole results. And the outcomes show that almost all correlation coefficients are significant, which indicates that the evident correlation does exist in monthly returns of these provinces (firms). Therefore, performing the next steps is logical. In theory, MST is constructed by the maximum one among all significant correlation coefficients. In addition, the correlation coefficients of the insurance market of province-level are greater than those of the insurance market of firm-level by comparing Table 1, Table 2 and Table 3, Table 4 simultaneously.

Table 1 The correlation coefficients between property insurance market of province-level and their significance

\begin{tabular}{cccccc}
\hline & Beijing & Tianjin & Hebei & Liaoning & Shanghai \\
\hline Beijing & 1 & & & & \\
Tianjin & $0.981^{* * *}$ & 1 & & & \\
Hebei & $0.953^{* * *}$ & $0.971^{* * *}$ & 1 & 1 & \\
Liaoning & $0.975^{* * *}$ & $0.985^{* * *}$ & $0.989^{* * *}$ & $0.969^{* * *}$ & 1 \\
Shanghai & $0.984^{* * *}$ & $0.984^{* * *}$ & $0.943^{* * *}$ & \\
\hline
\end{tabular}

Notes for this and below tables: $* * *, * *$, and $*$ mean that the correlation is significant at the $1 \%, 5 \%, 10 \%$ levels, respectively.

Table 2 The correlation coefficients between personal insurance market of province-level and their significance

\begin{tabular}{cccccc}
\hline & Beijing & Tianjin & Hebei & Liaoning & Shanghai \\
\hline Beijing & 1 & & & & \\
Tianjin & $0.932^{* * *}$ & 1 & & & \\
Hebei & $0.903^{* * *}$ & $0.923^{* * *}$ & 1 & 1 & \\
Liaoning & $0.935^{* * *}$ & $0.969^{* * *}$ & $0.947^{* * *}$ & $0.931^{* * *}$ & 1 \\
Shanghai & $0.887^{* * *}$ & $0.943^{* * *}$ & $0.853^{* * *}$ & \\
\hline
\end{tabular}

Table 3 The correlation coefficients between property insurance market of firm-level and their significance

\begin{tabular}{cccccc}
\hline & Anbang & Anhua & Bohai & Export Credit & Continent \\
\hline Anbang & 1 & & & & \\
Anhua & 0.060 & 1 & & & \\
Bohai & $0.509^{* * *}$ & 0.028 & 1 & 1 & 1 \\
Export Credit & 0.063 & 0.093 & $0.154^{*}$ & 0.043 & $0.319^{* * *}$ \\
Continent & $0.503^{* * *}$ & $0.207^{*}$ & & & \\
\hline
\end{tabular}

Following Mantegna ${ }^{[1]}$, we transform the correlation coefficient $\rho_{i j}$ into a distance metric, i.e., $d_{i j}=\sqrt{2\left(1-\rho_{i j}\right)}$, in order to obey the three axioms: (i) $d_{i j}=0$ if and only if $i=j$; (ii) 
$d_{i j}=d_{j i}$; and (iii) $d_{i j} \leq d_{i k}+d_{k j}$. Then, an $N * N$ distance matrix $D$ with elements $d_{i j}$ is acquired. Based on the distance matrix, we can construct the MST to describe taxonomy of one object with $N$ nodes and $N-1$ links. The commonly used method to construct MST is Kruskal's algorithm, which contains four procedures. Assuming a weighted connected graph $G$, whose node set and edge set are $V$ and $E$, respectively, we:

1) Let $V_{\text {new }}=\{u\}$, where $u$ is a node of $V$ and $E_{\text {new }}=\{\}$;

2) Choose the edge with the smallest weight $\langle u, v\rangle$, where $u$ belongs to $V_{\text {new }}$ while $v$ does not;

3) Put $v$ into $V_{\text {new }}$ and $E_{\text {new }}=E_{\text {new }}+\langle u, v\rangle$ if no loop appears in the new tree, otherwise discard it;

4) Repeat 2) and 3) until $V_{\text {new }}=V$.

Then the MST can be obtained through $V_{\text {new }}$ and $E_{\text {new }}$.

Table 4 The correlation coefficients between personal insurance market of firm-level and their significance

\begin{tabular}{cccccc}
\hline & China life & China Pacific & Ping An life & New China & Taikang \\
\hline China life & 1 & & & & \\
China Pacific & $0.913^{* * *}$ & 1 & & & \\
Ping An life & $0.833^{* * *}$ & $0.886^{* * *}$ & 1 & & \\
New China & $0.854^{* * *}$ & $0.932^{* * *}$ & $0.877^{* * *}$ & 1 & \\
Taikang & $0.762^{* * *}$ & $0.801^{* * *}$ & $0.769^{* * *}$ & $0.722^{* * *}$ & 1 \\
\hline
\end{tabular}

\subsubsection{Evaluation Criteria}

We use four criteria to characterize the MST for analyzing the disparities of geography and enterprise.

1) The mean distance measure (MDM), denoted as $L_{\mathrm{MDM}}$, describes the average distance between nodes:

$$
L_{\mathrm{MDM}}=\frac{2}{N(N-1)} \sum_{i=1}^{N-1} \sum_{j=i+1}^{N} d_{i j}
$$

where $d_{i j}$ is the element of the distance matrix $D$ calculated above and $N$ is the number of nodes.

2) The normalized tree length (NTL), also known as the average edge length of the tree, measures the amount of information the MST conveying:

$$
L_{\mathrm{NTL}}=\frac{1}{N-1} \sum_{d_{i j} \in \Theta} d_{i j}
$$

where $\Theta$ is the overall set of all the distances contained on the MST and $N-1$ is the number of edges of the MST.

3) The mean occupation layer (MOL) quantifies the density of MST, as Onnela, et al. ${ }^{[7]}$ 
defined:

$$
L_{\mathrm{MOL}}\left(v_{c}\right)=\frac{1}{N} \sum_{i=1}^{N} \operatorname{lev}\left(v_{i}\right),
$$

where $\operatorname{lev}\left(v_{i}\right)$ means the level of node $v_{i}$ with respect to the central node $v_{c}$ whose level is assumed to be zero.

4) The maximum degree is defined as the largest number of links connected directly with one node in a loopless graph of complex networks.

\section{Empirical Results}

\subsection{The Picture of China's Insurance Market}

Figure 1 presents the proportions of the property insurance and personal insurance in China's insurance market. On average, the property insurance only accounts for nearly $30 \%$ of the whole insurance market and the proportion of personal insurance is approximately $70 \%$, which means that the personal insurance dominates China's insurance market.

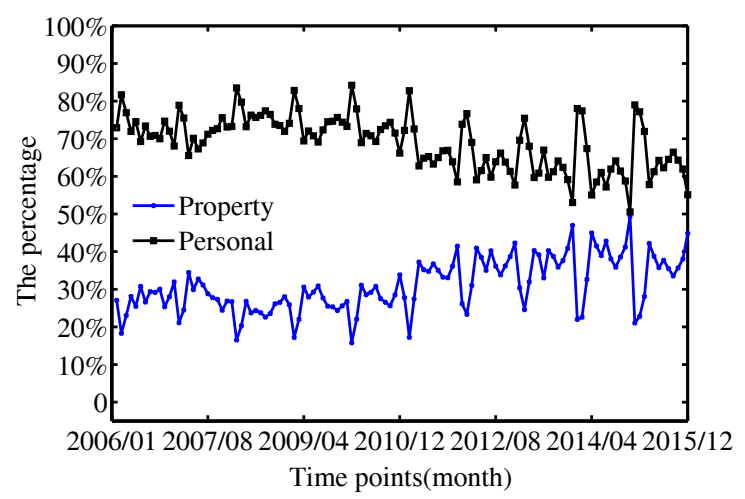

Figure 1 The proportions of the property insurance and personal insurance in China's insurance market

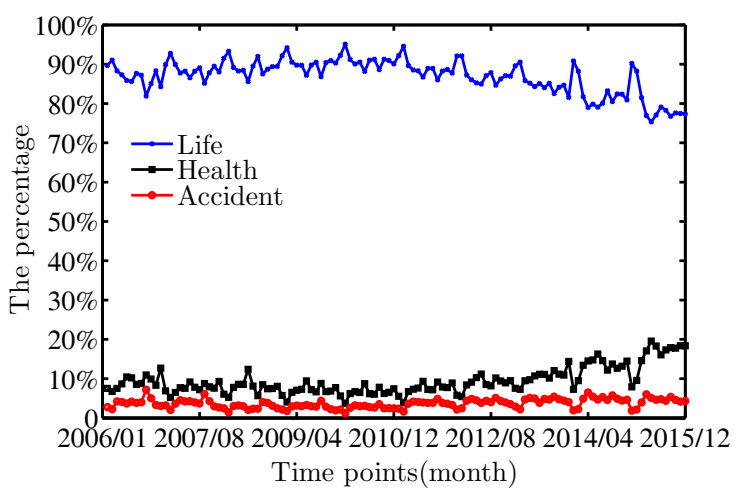

Figure 2 The proportions of life, health and accident insurance in the personal insurance market

In Figure 2, we display the proportions of life, health and accident insurances in the personal insurance market. We can see that: (i) The life insurance dominates the personal insurance 
market with a proportion of $80 \%$ or even more than $90 \%$, and (ii) the proportion of health insurance only occupies less than $10 \%$ and the accident insurance only $5 \%$.

\subsection{MSTs of Insurance Markets}

From Figure 3 (the province-level MST of the property insurance market), we can find that the degree of Zhejiang is the largest at 5, which implies that the Zhejiang province has the strongest ability to influence other provinces, including Chongqing, Sichuan, Beijing, Jiangsu and Guangdong. Jiangsu and Liaoning have the second largest degree at 4, indicating that they also have an intensive ability to affect other provinces. There is remarkable regional connection consisting of provinces in the property insurance market. For example, Jilin and Liaoning, Hunan and Hubei, Shanxi and Shaanxi are closely linked with each other. Note that Tibet has the farthest distance with other provinces, which may be associated with its geographical position and economic development level.

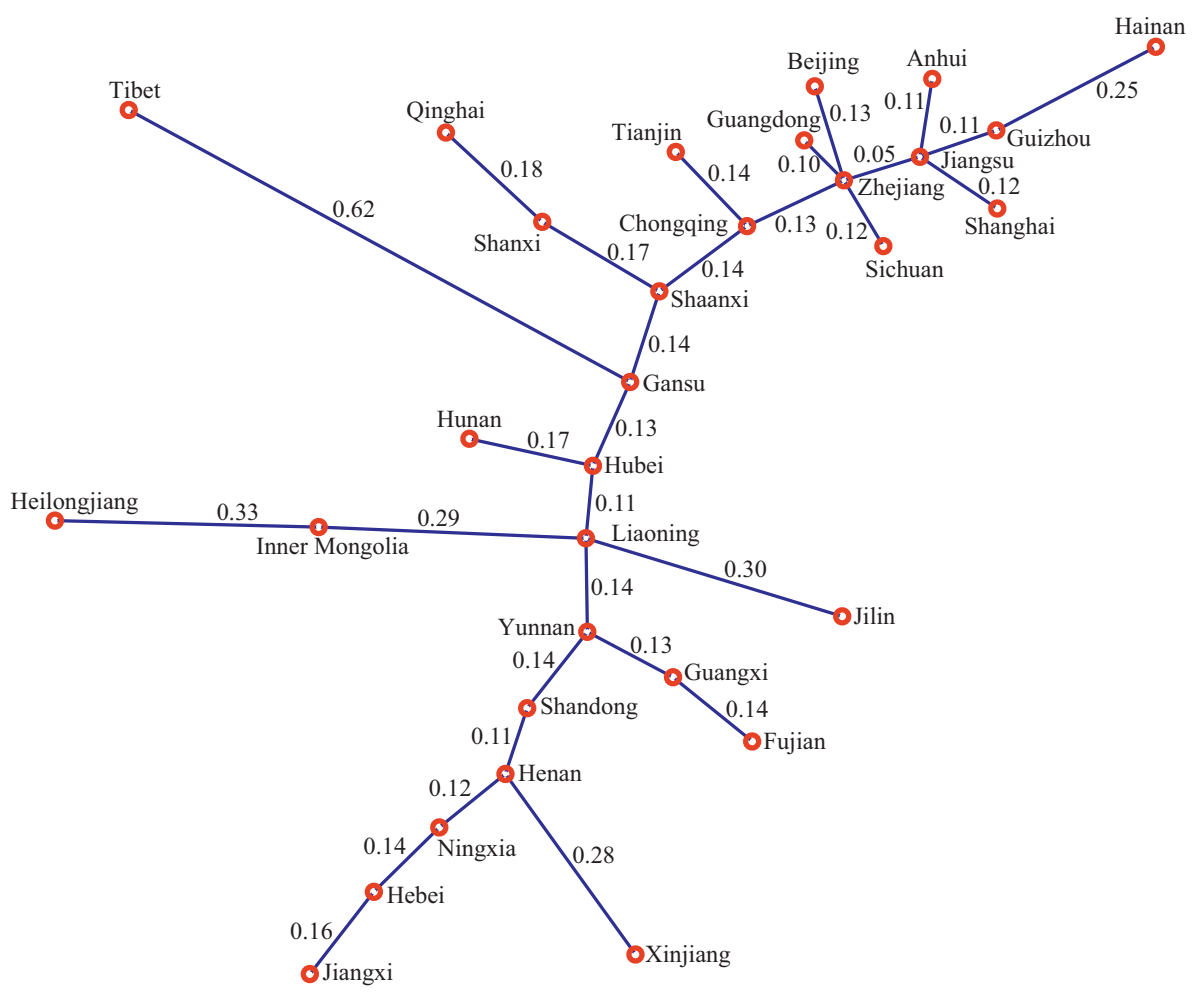

Figure 3 The province-level MST of the property insurance market

Figure 4 shows the firm-level MST of the personal insurance market. The central node is Xinjiang with the degree of 5 , which may have a relationship with support policies from the government, for example, tax preference and infrastructure construction. There are two subcentral nodes, namely Shandong and Zhejiang and both of them have the degree of 4. Overall, the distance between any two nodes (provinces) is much smaller when comparing with that in Figure 5 and Figure 6. Besides, we also observe obvious geographical connection in the personal insurance market. For example, Shanxi, Henan, Hubei and Hunan are directly connected. In this MST network, the connecting range with four central provinces is much greater when in 
comparison with the odd connection in Figure 3. Tibet still occupies the farthest position comparing with other provinces.

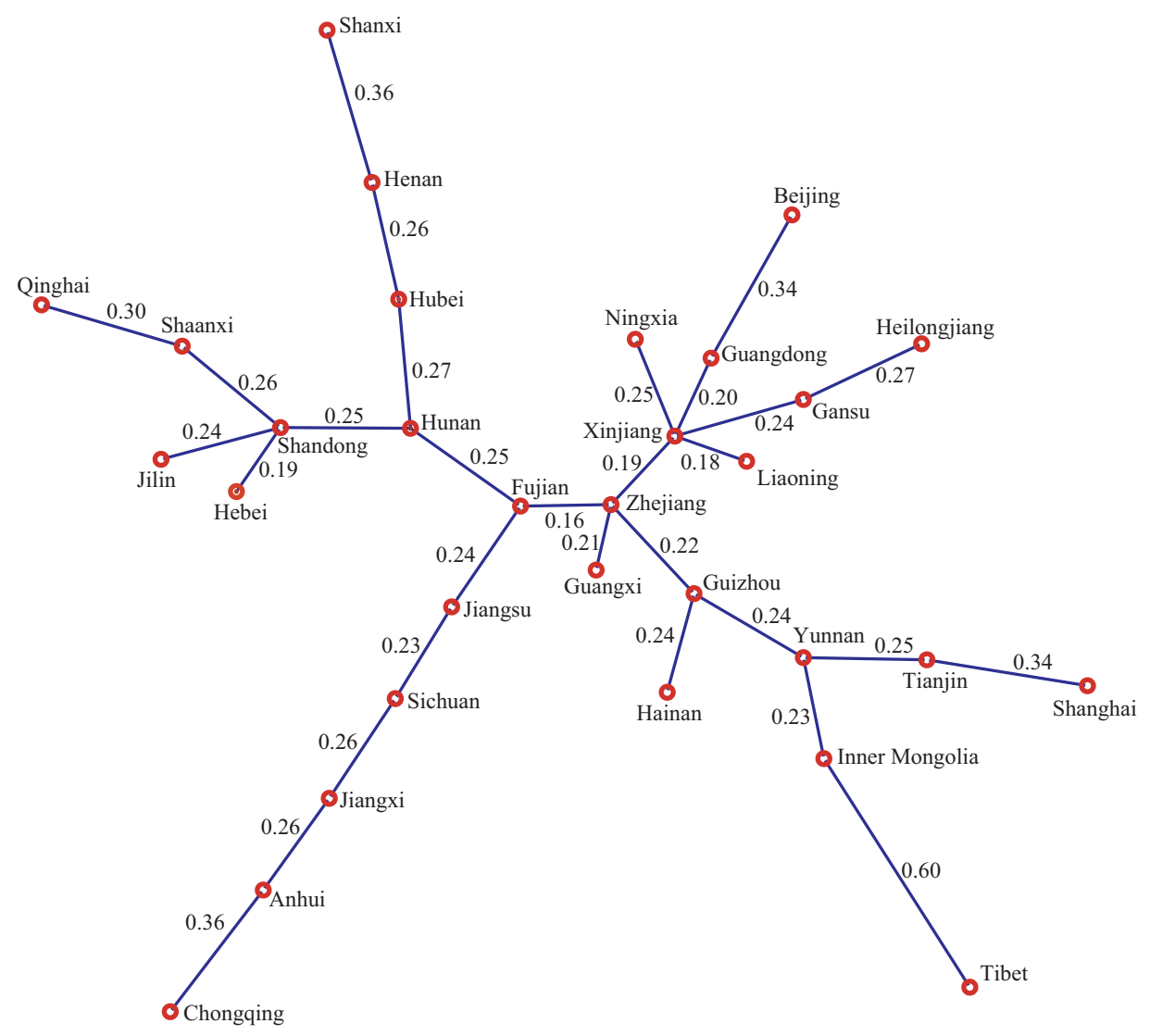

Figure 4 The province-level MST of the personal insurance market

By using the province-level and firm-level data, we construct the MSTs of the property and personal insurance markets in Figures 3 6. We denote these two MSTs as the provincelevel MST and the firm-level MST and present these two MSTs of the property and personal insurance markets, respectively.

It is easy to find from Figure 5 (the property insurance market of firm-level) that the domestic funded firms and foreign funded firms form two parts. As for the domestic funded firms, PICC is the central node with the degree of 5 , which has the strongest ability to influence other insurance firms. As a long-established firm, PICC has an excellent corporate governance and scientific management system and is strongly supported by government. In terms of foreign funded firms, Tokiomarine acts as the central node. Since the original data we get excludes the firms with missing data, the firms with complete data enter China's insurance market earlier and have long history in China certainly. As aforementioned, in the third stage of development of China's insurance market, AIA is the first foreign funded insurance company that enters China's insurance market, which witnesses the gradual open of China's insurance market to the world. 


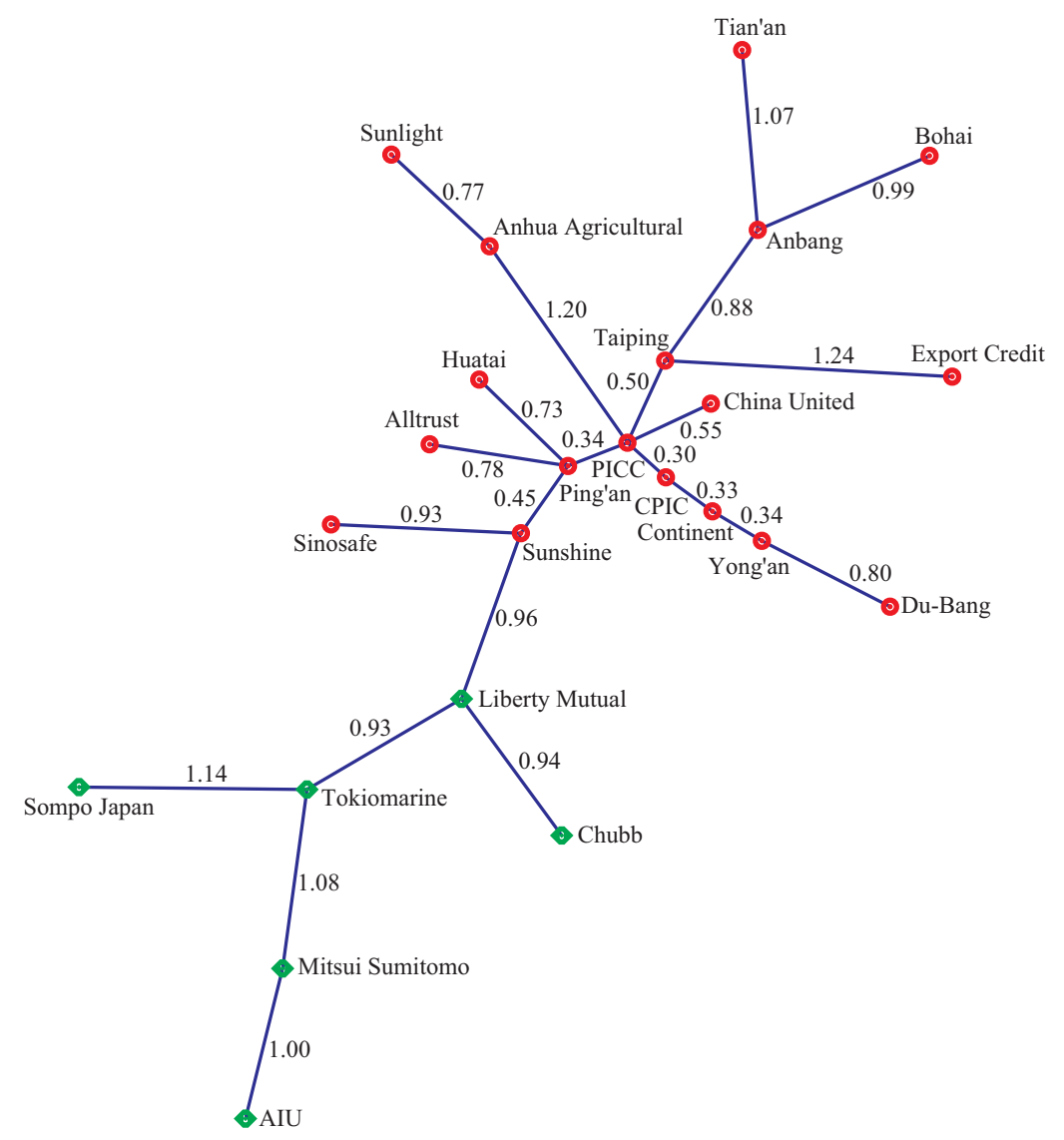

Figure 5 The firm-level MST of the property insurance market. Red circles and green diamonds denote domestic and foreign funded insurance firms, respectively

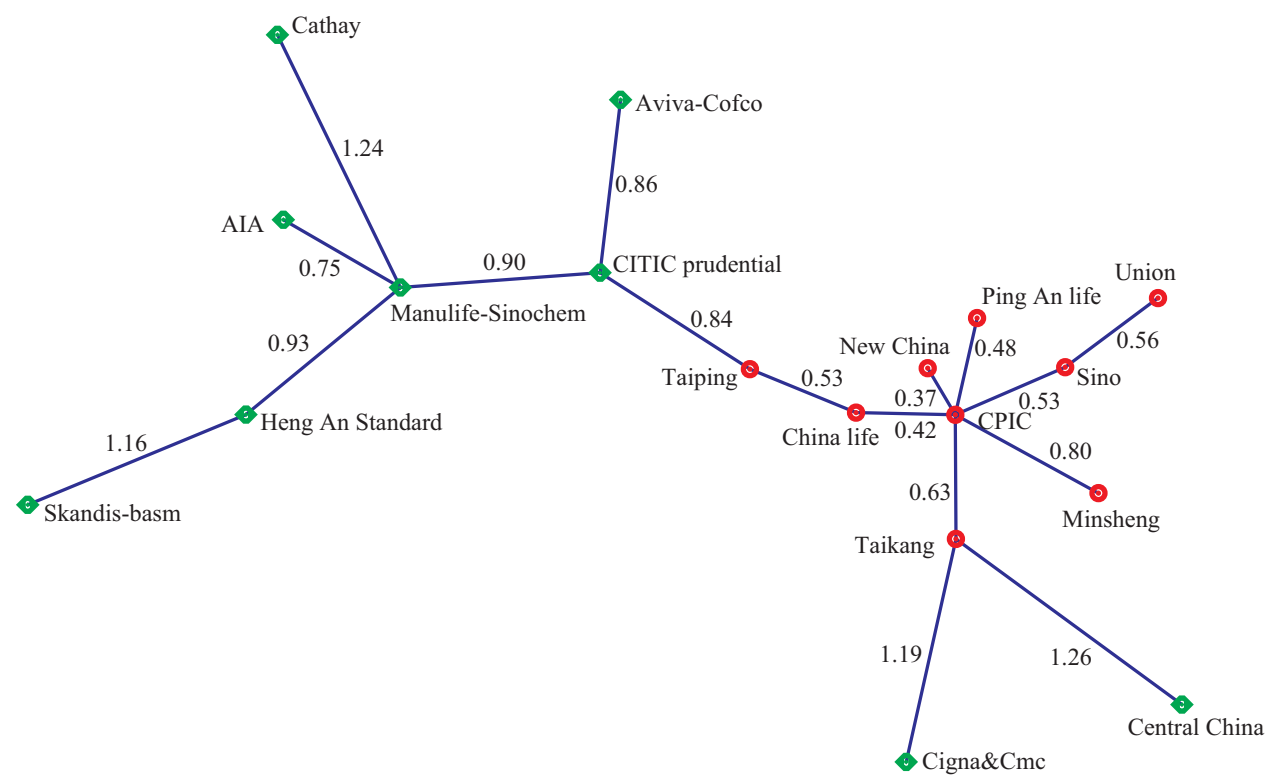

Figure 6 The firm-level MST of the personal insurance market. Red circles and green diamonds denote domestic and foreign funded insurance firms, respectively 
The MST in Figure 6 (the personal insurance market of firm-level) also consists of two parts: One is the domestic funded firms (Taiping, China life, CPIC, Ping An life, Minsheng, New China, Sino, Union and Taikang), and the other is the foreign funded firms (Skandis-basm, Heng An Standard, Cathay, Manulife-Sinochem, AIA, Aviva-Cofco and CITIC prudential) except for Central China and Cigna \& Cmc. In terms of domestic funded firms, CPIC has the strongest influence on other personal insurance firms. When it comes to foreign funded firms, the central node is Manulife-Sinochem, which may owe to its position that the first sino-foreign joint personal insurance firm. Central China and Cigna \& Cmc connects directly with a domestic personal firm (i.e., Taikang) because they are established later than other firms. The gradual improvement of environment of China's insurance market has also contributed to the close relationship. Therefore, we believe the entering of foreign funded firms prospers China's personal insurance market to some extent.

\subsection{Topology Analysis}

Table 5 presents five topological characteristics of province-level and firm-level MSTs of insurance markets. The second and third columns are insurance market data classified according to provinces and the fourth and fifth columns are insurance market data with different firms. It should be noted that there are 31 provinces, 24 property firms and 18 personal firms in the sample.

Table 5 Topological features of province-level and firm-level MSTs of the property and personal insurance markets

\begin{tabular}{cccccc}
\hline & \multicolumn{2}{c}{ Province-level MST } & & \multicolumn{2}{c}{ Firm-level MST } \\
\cline { 2 - 3 } \cline { 5 - 6 } & Property & Personal & & Property & Personal \\
\hline Number of nodes & 31 & 31 & & 24 & 18 \\
Mean distance measure & 0.2792 & 0.4310 & & 1.1647 & 1.1007 \\
Normalized tree length & 0.1729 & 0.2626 & & 0.7929 & 0.7916 \\
Mean occupation layer & 3.7097 & 3.4516 & & 3.2632 & 3.3333 \\
Maximum degree & 5 & 5 & 5 & 6 \\
\hline
\end{tabular}

For the mean distance measure, we find that the values of providence-level MSTs of the property and personal insurance markets are much smaller than those of firm-level MSTs. The correlation between provinces is much closer than that of different firms $(0.2792<1.1647$ and $0.4310<1.1007$ ). By comparing the values of the fourth row (normalized tree length), the outcomes of property and personal insurance of province-level (0.1729 and 0.2626) are also smaller than those firm-level (0.7929 and 0.7916). When it comes to mean occupation layer, there is minor difference among these four cases (3.7097, 3.4516, 3.2632 and 3.3333). According to Lee, et al. ${ }^{[2]}$, the smaller the mean occupation layer is, the more stable the market is. Our results demonstrate that the firm-level MST of the property insurance market has the most stable structure. The maximum degrees of these sub-markets $(5,5,5$ and 6$)$ are nearly the same with each other although the numbers of nodes of them are different. We can find that the personal insurance market of firm-level has a simpler structure and the hub node has a strong influence to affect other nodes. 
By comparing the property and personal insurance market of province-level, we can see that the mean distance between nodes of property insurance market is much shorter than that of personal insurance. Furthermore, the MST of the property insurance market is more compact than that of personal insurance market. However, the MST of the personal insurance market is more stable than that of property insurance market because its value of mean occupation layer is 3.4516 , which is smaller than that of corresponding value of property insurance market (3.7097). From the last two columns, it can be inferred that the distance between nodes are short for both the property and personal insurance markets after taking mean distance measure and normalized tree length into consideration at the same time. Nevertheless, the MST of the personal insurance market of firm-level has more stable structure than that of personal insurance market comparing with insurance market of province-level.

\section{Conclusions}

We use the MST network analysis to examine the disparity of China's property and personal insurance markets. The brief processes and results of our study are shown as follows:

(i) By investigating the total insurance market, we find that personal insurance account for the market share of approximately $70 \%$ while personal insurance occupies only $30 \%$. Besides, life insurance plays an important role in the personal insurance market with the market share more than $80 \%$.

(ii) We construct and discuss MSTs of property and personal insurance markets. On the one hand, Zhejiang has the strongest influence on other provinces and obvious regional connections between two neighboring provinces (such as Jilin and Liaoning, Hunan and Hubei, Shanxi and Shaanxi) appear in the MST in the property insurance market. On the other hand, Xinjiang is the central node in the MST of the personal insurance market. In addition, explicit connections between neighboring provinces (such as Shanxi, Henan, Hubei and Hunan, the number is more than two) appear again. Thus it can be seen that China's insurance market has obvious geographical connections. Furthermore, the domestic funded firms and foreign funded firms form two evident parts in both the property and personal insurance market. PICC has the maximum degree in the property insurance market and CPIC has the maximum degree in the personal insurance market.

(iii) We also explore the statistics of MST with four cases from two points of view, namely provinces and firms. On the whole, the connection between provinces is much closer than that between firms. Furthermore, despite of the fact that the numbers of nodes in MSTs are different, there are minor differences between the property insurance market and personal insurance market, no matter with the provinces or firms.

Now that there are some differences between provinces or firms in China's insurance market, the government should pay more attention on the provinces in remote areas, and give more financial support to promote their development like Xinjiang. In addition, the introduction of foreign capital is also good for the prosperity of China's insurance market, so more actions attracting foreign investment can also be taken into consideration. 


\section{References}

[1] Mantegna R N. Hierarchical structure in financial markets. The European Physical Journal B - Condensed Matter and Complex Systems, 1999, 11(1): 193-197.

[2] Lee J, Youn J, Chang W. Intraday volatility and network topological properties in the Korean stock market. Physica A: Statistical Mechanics and its Applications, 2012, 391(4): 1354-1360.

[3] Onnela J P, Chakraborti A, Kaski K, et al. Dynamics of market correlations: Taxonomy and portfolio analysis. Physical Review E, 2003, 68(5): 056110.

[4] Bonanno G, Vandewalle N, Mantegna R N. Taxonomy of stock market indices. Physical Review E, 2000, 62(6): R7615.

[5] Çukur S, Eryiğit M, Eryiğit R. Cross correlations in an emerging market financial data. Physica A: Statistical Mechanics and its Applications, 2007, 376: 555-564.

[6] Eryiğit M, Eryiğit R. Network structure of cross-correlations among the world market indices. Physica A: Statistical Mechanics and Its Applications, 2009, 388(17): 3551-3562.

[7] Onnela J P, Chakraborti A, Kaski K, et al. Dynamic asset trees and portfolio analysis. The European Physical Journal B - Condensed Matter and Complex Systems, 2002, 30(3): 285-288.

[8] Nie C X, Song F T, Li S P. Rényi indices of financial minimum spanning trees. Physica A: Statistical Mechanics and its Applications, 2016, 444: 883-889.

[9] Brida J G, Matesanz D, Seijas M N. Network analysis of returns and volume trading in stock markets: The Euro Stoxx case. Physica A: Statistical Mechanics and Its Applications, 2016, 444: 751-764.

[10] Radhakrishnan S, Duvvuru A, Sultornsanee S, et al. Phase synchronization based minimum spanning trees for analysis of financial time series with nonlinear correlations. Physica A: Statistical Mechanics and Its Applications, 2016, 444: 259-270

[11] Matesanz D, Ortega G J. Network analysis of exchange data: Interdependence drives crisis contagion. Quality \& Quantity, 2014, 48(4): 1835-1851.

[12] Wang G J, Xie C, Han F, et al. Similarity measure and topology evolution of foreign exchange markets using dynamic time warping method: Evidence from minimal spanning tree. Physica A: Statistical Mechanics and Its Applications, 2012, 391(16): 4136-4146.

[13] Wang G J, Xie C. Tail dependence structure of the foreign exchange market: A network view. Expert Systems with Applications, 2016, 46: 164-179.

[14] Di Matteo T, Aste T, Hyde S T, et al. Interest rates hierarchical structure. Physica A: Statistical Mechanics and Its Applications, 2005, 355(1): 21-33.

[15] Gilmore C G, Lucey B M, Boscia M W. Comovements in government bond markets: A minimum spanning tree analysis. Physica A: Statistical Mechanics and Its Applications, 2010, 389(21): 4875-4886.

[16] Coelho R, Gilmore C G, Lucey B, et al. The evolution of interdependence in world equity markets evidence from minimum spanning trees. Physica A: Statistical Mechanics and Its Applications, 2007, 376: 455-466.

[17] Wang G J, Xie C. Correlation structure and dynamics of international real estate securities markets: A network perspective. Physica A: Statistical Mechanics and Its Applications, 2015, 424: 176-193.

[18] Chen B, Jin T, Lu B, et al. Building interior layout reconstruction from through-the-wall radar image using MST-based method. EURASIP Journal on Advances in Signal Processing, 2014, 2014(1): 1-9.

[19] Belaid E, Rigo P, Cools M, et al. Bi-objective road and pipe network design for crude oil transport in the Sfax region in Tunisia. Procedia Engineering, 2016, 142: 108-114.

[20] Jothi R, Mohanty S K, Ojha A. Functional grouping of similar genes using eigenanalysis on minimum spanning tree based neighborhood graph. Computers in Biology and Medicine, 2016, 71: 135-148.

[21] Gomez D M, Torgler B, Ortega G J. Measuring global economic interdependence: A hierarchical network approach. The World Economy, 2013, 36(12): 1632-1648. 